\title{
On the Pull-Out Behavior of Hooked-End Shape Memory Alloys Fibers Embedded in Ultra-High Performance Concrete
}

\author{
Amir Ebrahim Akbari Baghal ${ }^{1}$, Ahmad Maleki $^{1, *}$, Ramin Vafaei $^{2}$ \\ ${ }^{1}$ Department of Civil Engineering, Maragheh Branch, Islamic Azad University, Maragheh, Iran \\ ${ }^{2}$ Department of Civil Engineering, Tabriz Branch, Islamic Azad University, Tabriz, Iran \\ Received 26 January 2021; received in revised form 13 May 2021; accepted 14 May 2021 \\ DOI: https://doi.org/10.46604/ijeti.2021.7060
}

\begin{abstract}
This study presents a three-dimensional non-linear finite element investigation on the pull-out behavior of straight and hooked-end Shape Memory Alloys (SMA) and steel fibers embedded in Ultra-High Performance Concrete (UHPC) using a single fiber pull-out model. A bilinear cohesive zone model is used to characterize the interfacial traction separation relationships. The Concrete Damage Plasticity (CDP) model is used to simulate UHPC, and the mechanical behavior is obtained through experimental tests. Parametric studies are conducted to evaluate the effects of fiber materials, fiber diameters, and hook angles on the load-displacement behavior. A good agreement between the numerical and experimental results is obtained. It is found that the hooked-end fibers with a smaller diameter and a hook angle of $40^{\circ}$ can be a better choice for structural application. Furthermore, it is observed that the use of SMA fibers significantly improves the pull-out performance between fibers and UHPC.
\end{abstract}

Keywords: pull-out behavior, UHPC, hooked-end fibers, shape memory alloy (SMA) fiber, finite element method

\section{Introduction}

Materials made of cement such as concrete and cement mortar are generally brittle and have very low tensile strength. Accordingly, various researchers have used different methods and additives, such as nanoparticles, polymeric materials, and fibers, to improve concrete strengths [1-5]. Studies show that the fibers with different types, materials, shapes, and aspect ratio are some of the best methods to improve the ductility, flexural strength, tensile strength, and energy absorption properties of concrete against external loads [6-9]. This improvement of mechanical properties is achieved by creating strain hardening behavior in the concrete-fiber mixture. The results of the studies show that using steel fibers can improve the maximum compressive and tensile strength of steel-reinforced concrete to achieve the values greater than $292 \mathrm{MPa}$ and $37 \mathrm{MPa}$, respectively. This is about 5-10 times higher than the properties of concrete without steel fibers [10]. Therefore, in recent years, many researchers have studied the effect of using different fibers on the mechanical properties of concrete.

Abdallah et al. [11] investigated the adhesion behavior of steel fibers with concrete, and showed that parameters such as fiber type, volume fraction, bond length, geometry, and orientation are effective on the pull-out properties of steel fibers embedded in concrete. According to their study, there are mainly two different mechanisms of adhesion between the matrix and the fibers, namely, physiochemical adhesion and static friction mechanism at the contact surface. The first mechanism is mainly defined by the properties of Interfacial Transition Zone (ITZ), which depends on the surface characteristics and the chemical reaction of the fibers with the matrix [12-14]. The second mechanism is highly dependent on the geometric shape of the fibers. Ellis et al. [15] studied the effect of the geometric shape of fibers on the pull-out behavior of steel fibers using the

* Corresponding author. E-mail address: Maleki_ah@yahoo.com 
finite element model. Cunha et al. [16] showed that hooked-end fibers behave differently from straight fibers, and the use of hook fibers increases the maximum pull-out force of the fibers from the concrete by 4.5 times. Using an analytical model, Alwan et al. [17] predicted a relationship for pull-out strength as a function of hook steel fibers slip. Abdallah and Rees [18] compared the pull-out behavior of different types of hook fibers from ordinary concrete. Kim and Yoo [19] examined the effects of fiber spacing, geometry, and loading rate on the pullout resistance of steel fibers in Ultra-High-Performance Concrete (UHPC).

With the development of modern engineering materials [20-22], the use of shape memory materials in construction applications has significantly increased. For example, Chang et al. [23] examined the applications of Shape Memory Alloys (SMA) materials in construction applications. Abdulridha et al. [24] cyclically loaded several superelastic Nitinol-reinforced concrete beams. Alam et al. [25] predicted the seismic behavior of concrete members reinforced with shape memory wires. Freed et al. [26] investigated the behavior of SMA wire-reinforced concrete for different weight percentages. Moser et al. [27] investigated the behavior of concrete reinforced by the use of star-shaped thin SMA fibers. By applying heat to the fibers, they created initial stress of about 122 Psi in the fibers, and applied the pre-stress to the concrete.

The previous studies show that although there have been many types of research in recent years on the pull-out behavior of fibers with different materials and geometries, the pull-out behavior of SMA fibers has not been addressed yet. Accordingly, the main purpose of the present study is to examine the finite elements and experimentally investigate the pull-out behavior between shape memory fibers and UHPC, as well as the effect of hook angle on bond strength. For this purpose, effects of key parameters, such as the fiber diameter and end-hook angle on the pull-out behavior of SMA and steel fibers, have been investigated using finite element simulation. The results obtained for SMA fibers are compared with the corresponding results on steel fibers. The numerical results are verified by comparing them to the results of the experimental tests.

\section{Numerical Simulation}

\subsection{Structure modeling}

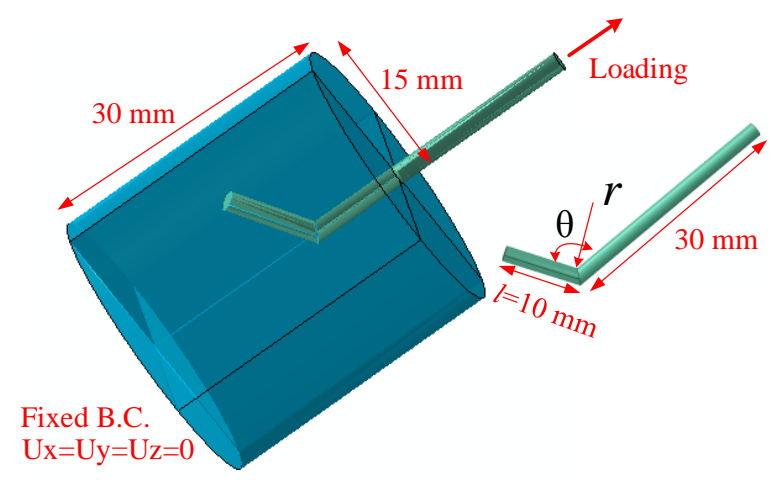

Fig. 1 Geometrical model of concrete with shape memory fiber

Fig. 1 shows a schematic configuration of the finite element model of SMA fiber pulled out from concrete. The radius of hook SMA fibers is $r$, and its length and end-hook angle are $l$ and $\theta$, respectively, as show in Fig. 1 . The size of the matrix must be large enough to negate the effect of boundary conditions on the pull-out behavior, so its radius is selected approximately 20 times the radius of the fibers. For this reason, the cylindrical matrix with length of $30 \mathrm{~mm}$ and the diameter of $30 \mathrm{~mm}$ are considered. The fibers are subjected to uniaxial tension by applying displacement $\delta$ to the free end of the fibers to measure the generated force $P_{a}$. The bottom end of the concrete specimen is completely fixed to apply the clamped boundary conditions and to constraint the matrix. As can be seen in the finite element model, the geometry is made up of three different parts, namely, concrete, SMA fibers, and the ITZ between the two materials. In this research, the concept of the ITZ model is used to simulate the adhesion of the fibers with concrete, and ABAQUS commercial code is used for finite element simulation of the 
fiber pull-out. The shape memory fibers are meshed using C8D3R cubic elements with an average size of $90 \mu \mathrm{m}$. The UHPC are meshed by C8D3R elements with an average size of $0.1 \mathrm{~mm}$. It should be noted that these mesh dimensions are selected after analyzing mesh sensitivity.

\subsection{The interaction between fibers and concrete}

Since the fibers are hook-type, to simulate the pull-out behavior, the traction-separation behavior is used, as schematically illustrated in Fig. 2.

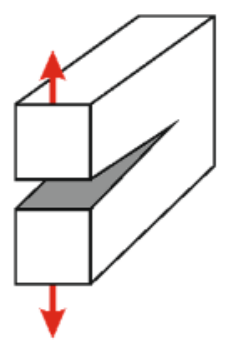

(a) Mode I: opening

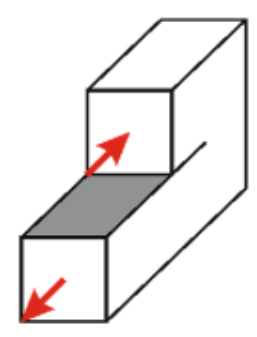

(b) Mode II: Sliding

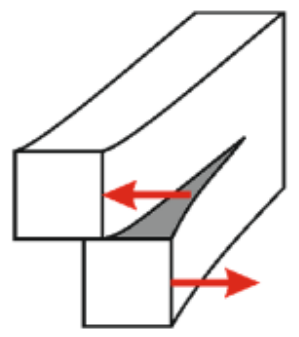

(c) Mode III: Tearing

Fig. 2 Traction-separation behavior of the finite element model in three fracture modes [28]

The structural relationship between traction stress and separation is as follows:

$$
T=\left\{\begin{array}{l}
T_{n} \\
T_{s} \\
T_{t}
\end{array}\right\}=\left[\begin{array}{lll}
K_{n n} & K_{n s} & K_{n t} \\
K_{n s} & K_{s s} & K_{s t} \\
K_{n t} & K_{s t} & K_{t t}
\end{array}\right]\left\{\begin{array}{l}
\delta_{n} \\
\delta_{s} \\
\delta_{t}
\end{array}\right\}=K \delta
$$

where $T_{n}, T_{s}$, and $T_{t}$ are separation stresses in vertical, first shear, and second shear directions, respectively. $K, \delta_{n}, \delta_{s}$, and $\delta_{t}$ are the stiffness matrix and displacements in vertical, first shear, and second shear directions, respectively.

Assuming that the vertical and shear components are non-coupled, Eq. (1) is transformed as follows:

$$
T=\left\{\begin{array}{l}
T_{n} \\
T_{s} \\
T_{t}
\end{array}\right\}=\left[\begin{array}{ccc}
K_{n n} & 0 & 0 \\
0 & K_{s s} & 0 \\
0 & 0 & K_{t t}
\end{array}\right]\left\{\begin{array}{l}
\delta_{n} \\
\delta_{s} \\
\delta_{t}
\end{array}\right\}
$$

The mechanical behavior of the contact surface is simulated using the traction-separation law and based on the bilinear cohesive zone model. As shown in Fig. 3, in the absence of any kind of failure, the linear contact surface behavior is assumed to be linear which is true until the occurrence of the failure. In this model, it is assumed that all the mechanisms of ITZ and the fracture process can be considered by three parameters: maximum shear stress or bond strength $\left(T_{\max }\right)$, maximum critical separation $\delta_{\max }$, and the separation energy $G_{\mathrm{c}}$.

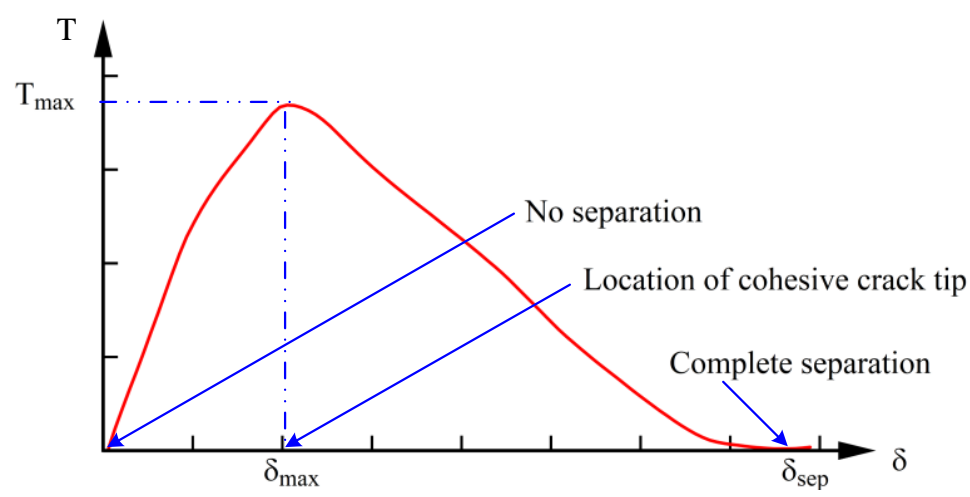

Fig. 3 Traction-separation law for modeling cohesive failure 


\subsection{Defining mechanical properties of materials}

The SMA used in this research is NiTi memory alloy by weight of 50.8\% nickel and $49.2 \%$ titanium made by Daido Steel Co., Ltd., Japan. Fig. 4 shows the stress-strain diagram of the SMA fibers used in the present study. To express the super-elastic behavior of SMA fibers, the mechanical behavior of the SMA materials is based on the constitutive equation of Zhou et al. [29]. Based on this constitutive equation, the stress-strain relationship has been defined in ABAQUS using the UMAT subroutine. The required parameters are Young's modulus for two phases of austenite and martensite, austenite martensite starting stress, austenite to martensite finishing stress, martensite to austenitic starting stress, martensite to austenitic finishing stress, and maximum residual strain. Table 1 illustrates the mechanical properties of NiTi required for numerical modeling.

Table 1 Mechanical properties of NiTi fibers*

\begin{tabular}{|c|c|c|c|c|c|}
\hline $\begin{array}{c}\text { Maximum } \\
\text { strain }\end{array}$ & $\begin{array}{c}\text { Martensite to } \\
\text { austenitic finishing } \\
\text { stress }\end{array}$ & $\begin{array}{c}\text { Martensite to } \\
\text { austenitic starting } \\
\text { stress }\end{array}$ & $\begin{array}{c}\text { Austenite to } \\
\text { martensite finishing } \\
\text { stress }\end{array}$ & $\begin{array}{c}\text { Austenite martensite } \\
\text { starting stress }\end{array}$ & $\begin{array}{c}\text { Young's } \\
\text { modulus }\end{array}$ \\
\hline$\varepsilon_{L}=0.90 \%$ & $\sigma_{f}^{S A}=120 \mathrm{MPa}$ & $\sigma_{s}^{S A}=175 \mathrm{MPa}$ & $\sigma_{f}^{A S}=342 \mathrm{MPa}$ & $\sigma_{f}^{A S}=340 \mathrm{MPa}$ & $E_{a}=67 \mathrm{GPa}$ \\
\hline
\end{tabular}

*Based on Daido Steel Co., Ltd., Japan Database.

In this study, the Concrete Damage Plasticity (CDP) behavior model of UHPC is used to simulate the nonlinear behavior of concrete materials. The parameters in this material model are dilation angle $\psi$, plastic potential eccentricity $e$, the ratio of biaxial to the uniaxial compressive strength of concrete $f_{b o} / f_{c o}$, loading coefficient $K_{c}$, and viscosity parameter.

The uniaxial stress-strain in compression and tension are required to evaluate the hardening/softening behavior of UHPC. Compressive tests on the standard cylinder specimens $(100 \mathrm{~mm} \times 200 \mathrm{~mm})$, with a procedure conforming to ASTM C39, are performed to determine the compressive strengths and stress-strain curves of the UHPC materials. Meanwhile, the tensile properties of the UHPC materials are identified using direct tensile tests on the dog-bone specimens. A steel frame containing two Linear Variable Differential Transformers (LVDTs) is attached with a gauge length of 90 mm. A uniaxial force is monotonically applied through a universal testing machine with a maximum capacity of $2 \mathrm{kN}$, and the loading rate of 0.6 $\mathrm{mm} / \mathrm{min}$ is determined by the speed of the stroke. The tensile force is measured from a load cell at the crosshead, and both the load and elongation data are collected by astatic data logger. The tensile stress is then calculated by dividing the measured load by the cross-sectional area, and the strain is obtained by dividing the elongation by the gauge length.

The configuration and test setup are presented in Fig. 5. Also, the stress-strain curves of UHPC in both tensile and compressive loads obtained from the direct tensile test and compression test are shown in Fig. 5. Table 2 shows the mechanical properties used for UHP concrete. Table 3 demonstrates the geometric properties of hooked-end fibers for finite element modeling.

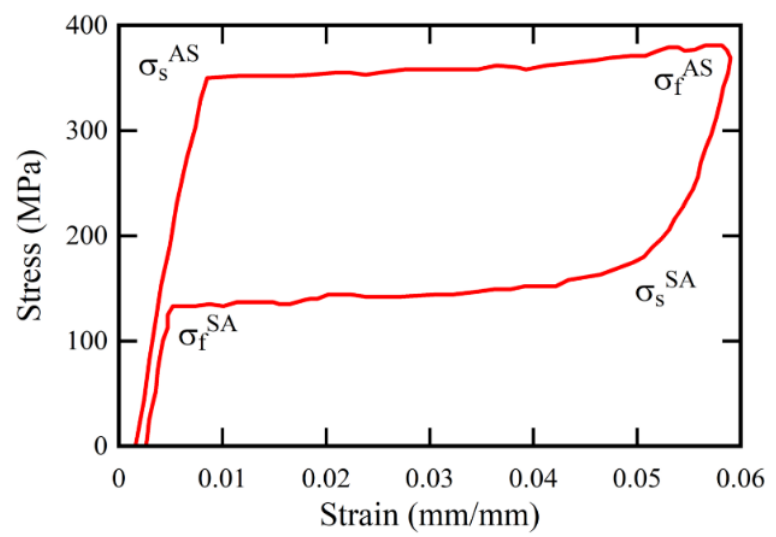

Fig. 4 Stress-strain curve of NiTi SMA fiber based on Daido Steel Co., Ltd., Japan Database 


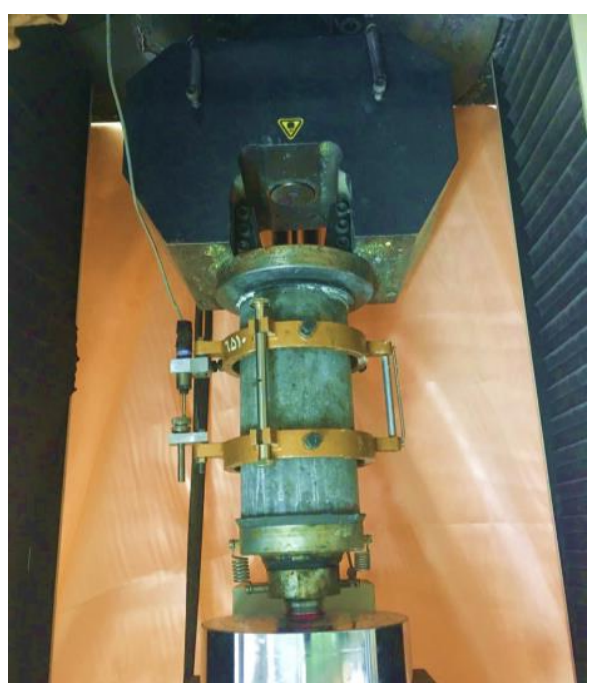

(a) Uniaxial compression test setup

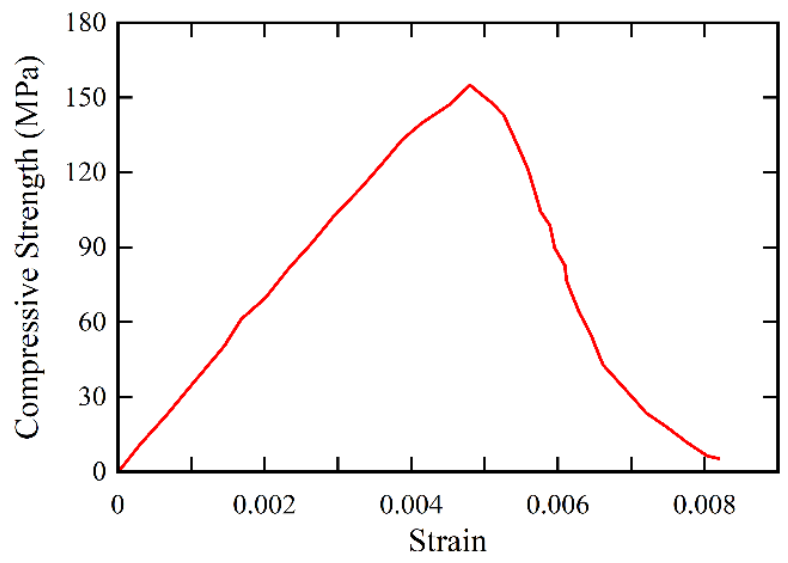

(c) Compressive stress-strain curve

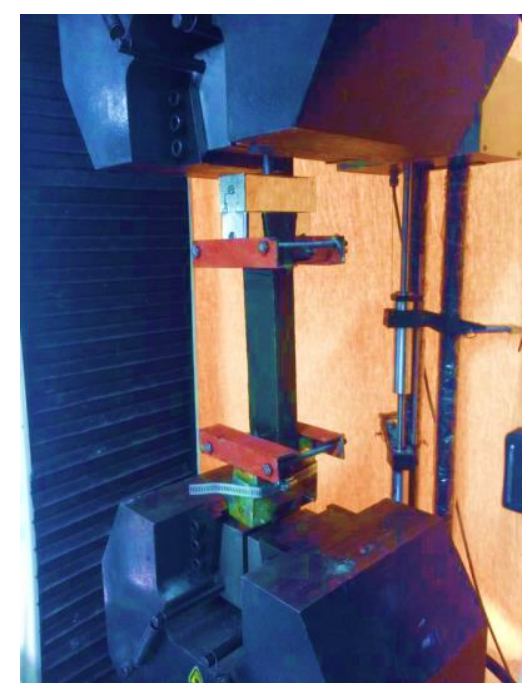

(b) Uniaxial tensile tests setup

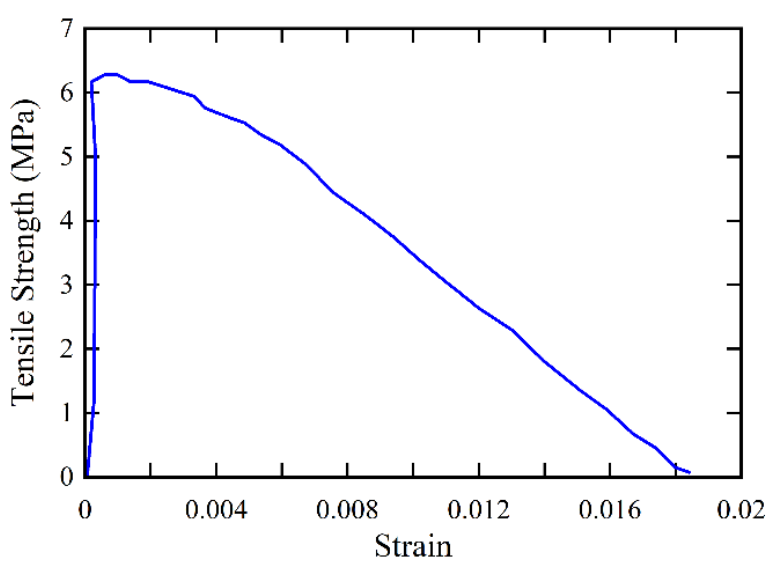

(d) Tensile stress-strain curve

Fig. 5 Configuration and test setup for uniaxial compression and tensile tests

Table 2 Mechanical properties of UHPC obtained from direct tensile and compressive stress-strain curves

\begin{tabular}{|c|c|c|c|c|c|}
\hline \multirow{2}{*}{$\begin{array}{c}\text { Concrete } \\
\text { properties }\end{array}$} & $\begin{array}{c}\text { Compressive } \\
\text { strength }\end{array}$ & $\begin{array}{c}\text { Modulus of } \\
\text { elasticity }\end{array}$ & Tensile strength & Fracture energy & Poisson's ratio \\
\cline { 2 - 6 } & $158 \mathrm{MPa}$ & $44680 \mathrm{MPa}$ & $6.26 \mathrm{MPa}$ & $0.067 \mathrm{~N} / \mathrm{mm}$ & 0.18 \\
\hline \multirow{2}{*}{$\begin{array}{c}\mathrm{CDP} \\
\text { parameters }\end{array}$} & $\psi$ & $e$ & $f_{b o} / f_{c o}$ & $K_{\mathrm{c}}$ & $\begin{array}{c}\text { Viscosity } \\
\text { parameter }\end{array}$ \\
\cline { 2 - 6 } & 39 & 0.1 & 1.16 & $2 / 3$ & 0.0001 \\
\hline
\end{tabular}

Table 3 Geometric properties of hooked-end fibers

\begin{tabular}{|c|c|c|c|}
\hline No. & Material & $\begin{array}{c}\text { Fiber diameter, } \\
d_{\mathrm{f}}(\mathrm{mm})\end{array}$ & Angle \\
\hline $1,2,3,4$ & \multirow{3}{*}{ SMA } & 0.5 & $0,20,40,90$ \\
\hline $5,6,7,8$ & & 1.5 & $0,20,40,90$ \\
\hline $9,10,11,12$ & & 2.0 & $0,20,40,90$ \\
\hline $13,14,15,16$ & \multirow{3}{*}{ Steel } & 0.5 & $0,20,40,90$ \\
\hline $17,18,19,20$ & & 1.5 & $0,20,40,90$ \\
\hline $21,22,23,24$ & & 2.0 & $0,20,40,90$ \\
\hline
\end{tabular}

\section{Experimental Pull-Out Test}

Pull-out tests of the SMA and steel fibers are performed on UHPC samples containing single fibers, using a universal testing machine. The capacity of the load cell is $2 \mathrm{kN}$, and a uniaxial pull-out force is monotonically applied with a loading rate of $1.5 \mathrm{~mm} / \mathrm{min}$. The pull-out force-displacement curves for each type of hook-end fiber are recorded. The pull-out load is measured from a load cell affixed to the crosshead, and the slip is measured from the internal LVDT of the universal testing 
machine. However, the elastic elongation of fiber during the pull-out test is neglected. The maximum pull-out load, the displacement at maximum pull-out load, and the area under the pull-out load-displacement curve of each fiber type are also calculated by analyzing the pull-out force-displacement curves. The UHPC specimen is made as rectangular cubes with dimensions $25 \times 25 \times 60 \mathrm{~mm}^{3}$. Fig. 6 shows how the samples containing single steel and SMA fiber are placed inside the universal testing machine. The test is completed when the fibers are completely pulled out.

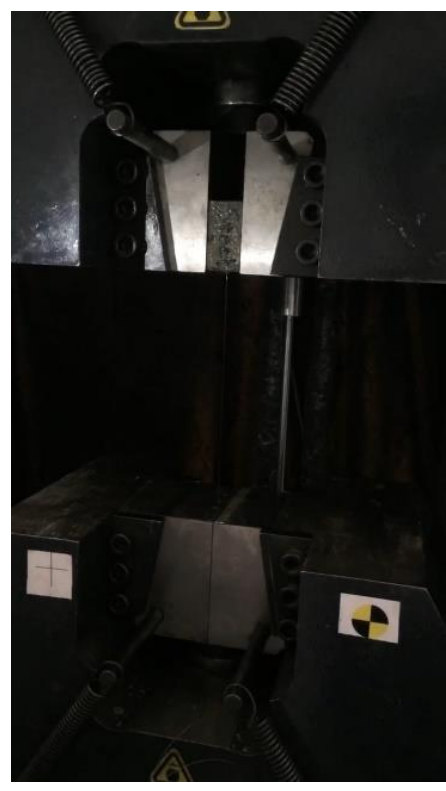

(a) SMA fiber

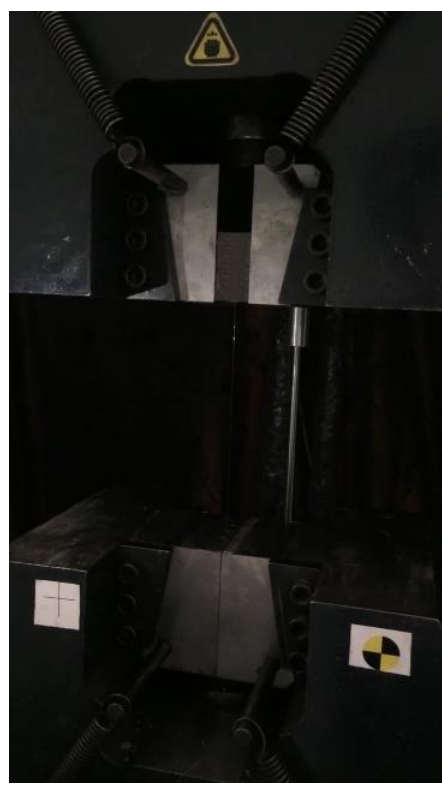

(b) Steel fiber

Fig. 6 SMA and Steel fiber pull-out test setup

\section{Results and Discussion}

First, the parameters of the ITZ model are determined using experimental tests, and then the impact of different parameters on the adhesion behavior of hooked-end SMA fibers with concrete is studied. The interaction between fibers and concrete is considered by using contact constraint and defining adhesive elements, and the parameters of the adhesive zone model are determined so that the force-displacement curve obtained from the finite element model is compliant with the experimental results of the pull-out test performed on steel and SMA fibers. After calibrating the finite element results of the pull-out test, the unknown constants of the ITZ model are obtained as Table 4.

Using the values presented in Table 4, the force-slip curve obtained by finite element model and the results of experimental tests of samples No. 01 and No. 13 are shown in Fig. 7. As can be seen, there is a good agreement between computational and experimental results and the maximum pull-out strength between the experimental test and the finite element model, demonstrating about 7\% error. On this basis, it can be stated that the finite element model predicts the pull-out behavior between SMA fibers and concrete with very suitable accuracy so that the effect of different parameters can be studied using it.

The examination of the force-slip curves presented in Fig. 7 for steel and SMA fibers shows that for the same fiber properties, the pull-out force of the SMA fibers is greater than the corresponding values of steel fibers. For example, for fibers with a diameter of $0.5 \mathrm{~mm}$, the maximum pull-out force of the SMA fibers is about $13 \%$ higher than that of the corresponding steel fibers, which can be attributed to the strong surface pull-out forces between the SMA fibers and the concrete. Also, results show that the amount of displacement required for separation of the SMA fibers is higher than the corresponding steel fibers, which is $0.59 \mathrm{~mm}$ and $0.78 \mathrm{~mm}$ for the SMA and steel fibers, respectively. Therefore, the use of SMA fibers increases the displacement of fibers by about $32 \%$, which is considerable. 
Table 4 ITZ model parameters for defining the interaction of fibers with UHPC matrix

\begin{tabular}{|c|c|c|c|}
\hline Fiber type & $T_{\max }$ & $\delta_{\max }$ & $G_{c}$ \\
\hline SMA fiber & $9.04 \mathrm{MPa}$ & $3 \times 10^{-3} \mathrm{~mm}$ & $0.21 \mathrm{MPa} . \mathrm{mm}$ \\
\hline Steel fiber & $7.15 \mathrm{MPa}$ & $2.6 \times 10^{-3} \mathrm{~mm}$ & $0.18 \mathrm{MPa} . \mathrm{mm}$ \\
\hline
\end{tabular}

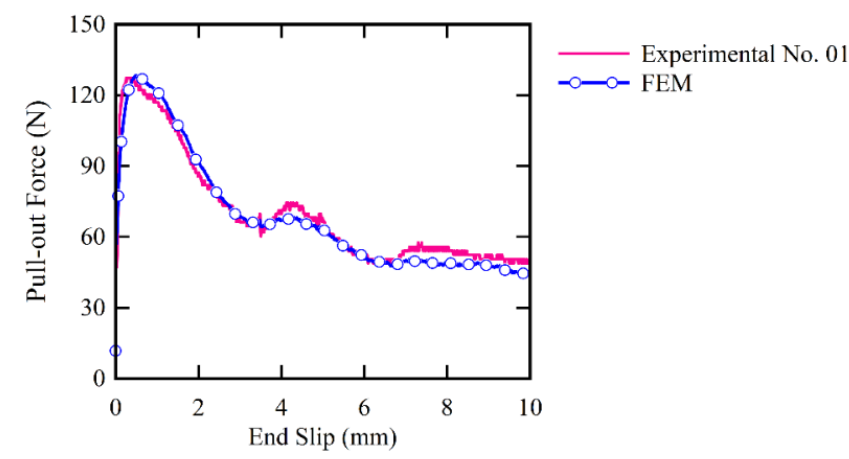

(a) SMA fibers (sample No. 01)

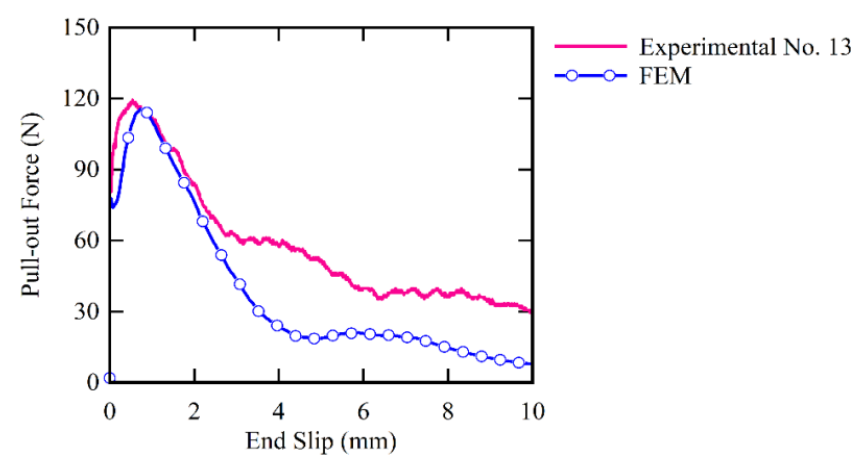

(b) Steel fibers (sample No. 13)

Fig. 7 Force-slip curve of the finite element model and results of the experimental pull-out test

In Fig. 8, the distribution of plastic stresses for different values of pull-out strength for sample No. 03 is shown. As can be seen at the beginning of applying the pull-out force, the upper parts of the fibers are first affected by higher stresses, and by overcoming the chemical and frictional adhesion forces, the plastic stress distributions gradually increase along the fibers. By more increasing the applied force, the contact surface of the fibers is completely removed from the concrete and the fibers begin to be completely separated from concrete, in which case the mechanical adhesion created at the hooked-end bending location forms the force transfer local points between the fibers and the matrix. According to the stress distribution in the hooked-end SMA fibers demonstrated in Fig. 9, it is observed that the maximum stresses in the fibers are at the bending location of the fibers. By increasing the hooked angle, the maximum stresses increase due to increasing the mechanical adhesion of the fibers with concrete. The results show that the maximum stresses in the SMA fibers with angles of 20, 40, and 90 degrees are $444 \mathrm{MPa}, 610 \mathrm{MPa}$, and $906 \mathrm{MPa}$, respectively. Given that these stress values are higher than the stresses of SMA fibers direct phase conversion, it can be concluded that when removing the SMA fibers from concrete, the austenite to martensite phase conversion occurs in these fibers, resulting in different adhesive behavior depending on displacement.

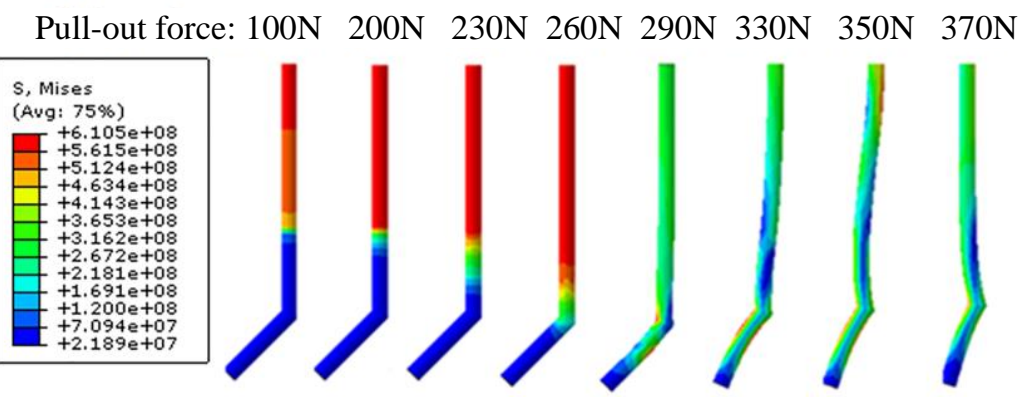

Fig. 8 SMA fiber pull-out steps with 40-degree hook angle (No. 11) for different applied force values

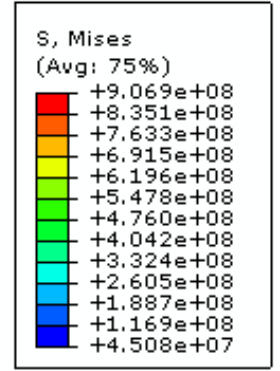

(a) 20 degrees

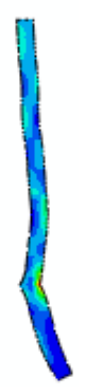

Fig. 9 Distribution of generated stress in hook-shaped

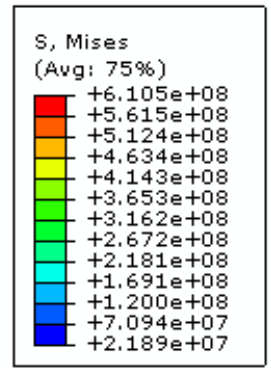

(b) 40 degrees

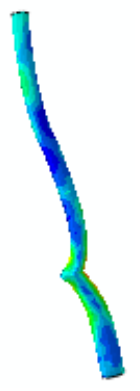

ped SMA fibers with different angles
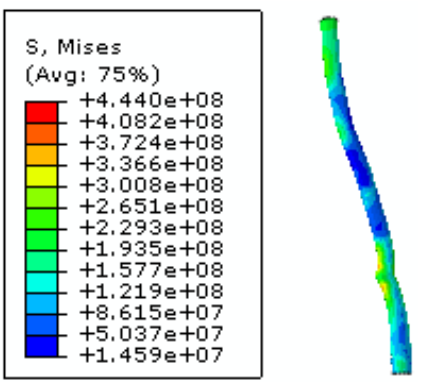

(c) 90 degrees 
Figs. 10 and 11 show the slip-force curves for different SMA and steel fiber samples, respectively. By examining the pull-out behavior of simple and hooked-end fibers, it is observed that in simple fibers (straight fiber), slipping out occurs depending on the amount of frictional resistance of the fibers, resulting in slip failure. In hooked-end fibers, in addition to chemical adhesion and frictional stability, mechanical fastening between concrete and the hooked-end part of the fibers increases bond strength. Among the adhesive mechanisms, the shear bond of hooked-end fibers to concrete is particularly important because it creates the greatest bond stress. In this bond mechanism, the force is transmitted by engaging the curved portion of the fibers and concrete plastic hinges.

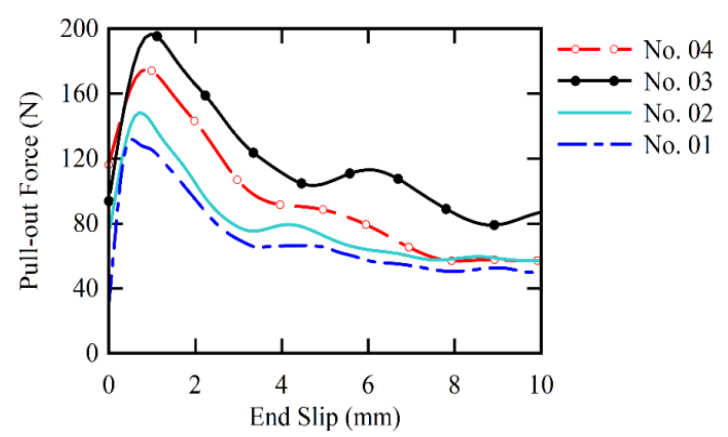

(a) Force-slip curve for samples No. 01 to No. 04
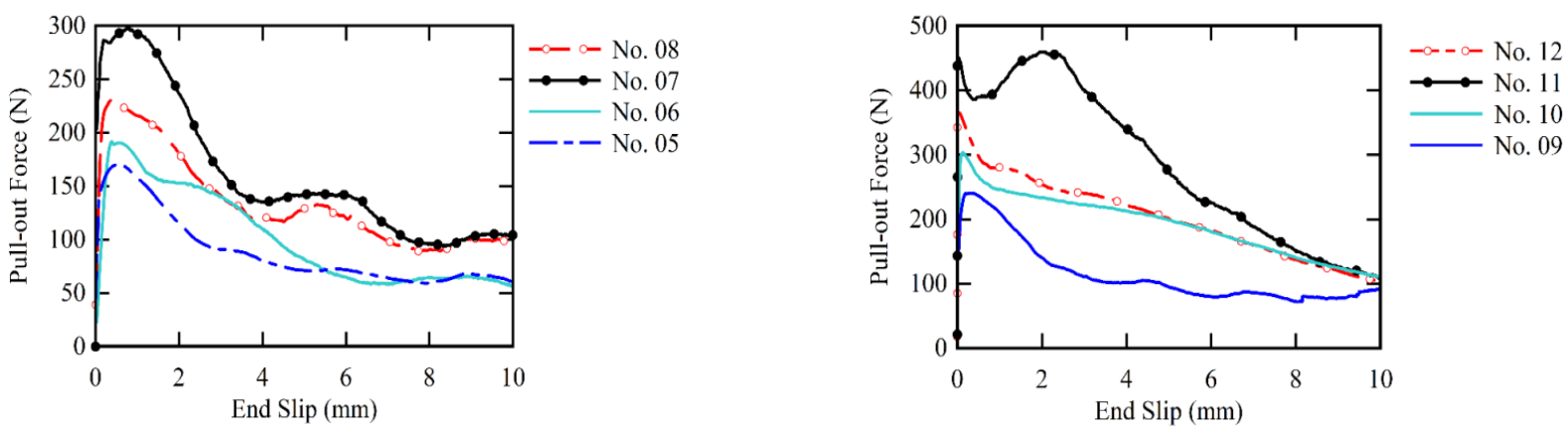

(b) Force-slip curve for samples No. 05 to No. 08

(c) Force-slip curve for samples No. 09 to No. 12

Fig. 10 Force-slip curve for different samples of the SMA fibers (based on Table 3)

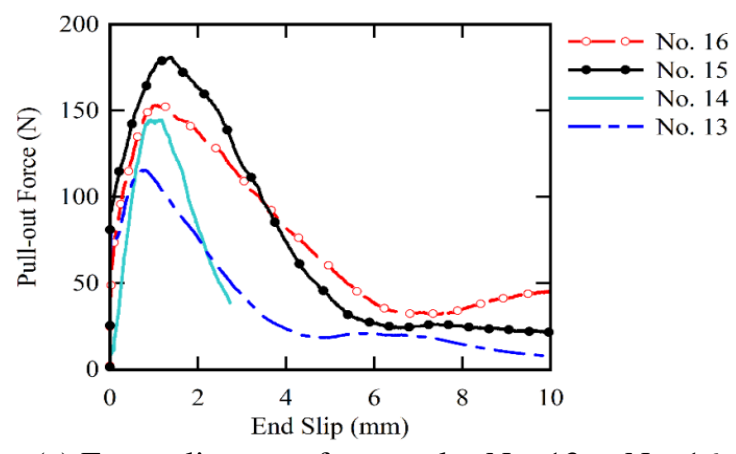

(a) Force-slip curve for samples No. 13 to No. 16

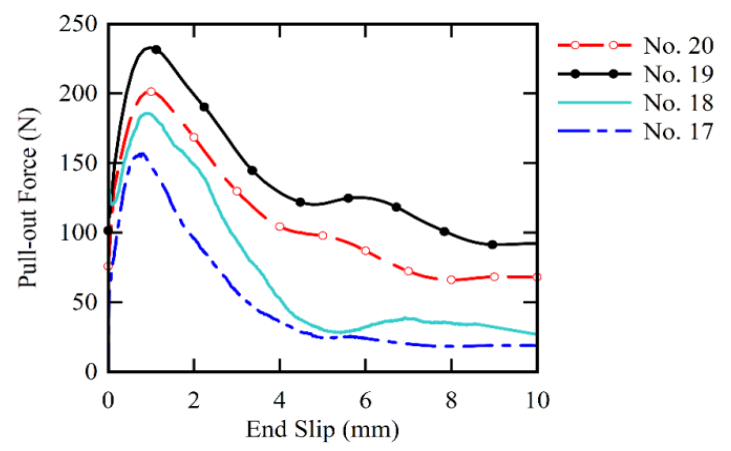

(b) Force-slip curve for samples No. 17 to No. 20

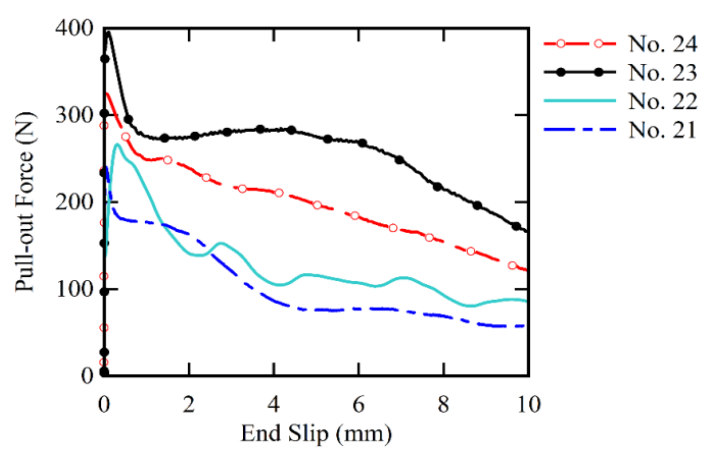

(c) Force-slip curve for samples No. 21 to No. 24

Fig. 11 Force-slip curve for different steel fiber specimens (based on Table 3) 
The notable result of the slip-force curves is that there are different mechanisms of fiber pull-out depending on the diameter and hook angle of the fiber. As an example, for No. 04 , it is observed that three different mechanisms occur during the pull-out of these fibers: 1) Elastic shear bond between the fibers and the matrix at the contact surface. 2) Frictional shear bond that allows relative slip at the interface of the fibers and the matrix, and occurs when the primary adhesion is eliminated. 3) Mechanical bond that creates the force transfer local points between the fibers and the matrix. These three different bond mechanisms are illustrated in Fig. 12(a). Also, the study of SMA fiber pull-out behavior shows that in some cases there are two different mechanisms for interfacial separation of these fibers. The first mechanism is complete separation before the martensitic phase conversion, and the other mechanism is the separation after the martensitic phase conversion. According to the slip-force curve shown for sample No. 12 (Fig. 12(b)), it is observed that the surface separation occurs up to point A, but the surface bond stresses increase again due to the conversion of the martensite phase of the SMA fibers to austenite. After this point, the shear bond between the fibers and concrete decreases as the force is increased, and the fibers begin to separate from concrete. The examination of the results of different samples shows that in some cases the shear bond is large enough, and phase conversions of the SMA fibers occur. The phase conversion of the SMA fibers from martensite to austenite increases the maximum separation force, and for sample No. 12, the magnitudes of this force for the martensite and austenite phases are 471 $\mathrm{N}$ and $436 \mathrm{~N}$, respectively.

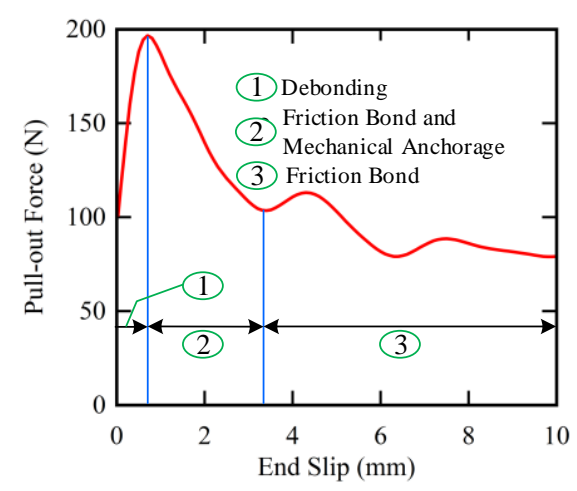

(a) SMA with $d_{\mathrm{f}}=0.5 \mathrm{~mm}$ and angle $90^{\circ}$ (No. 04)

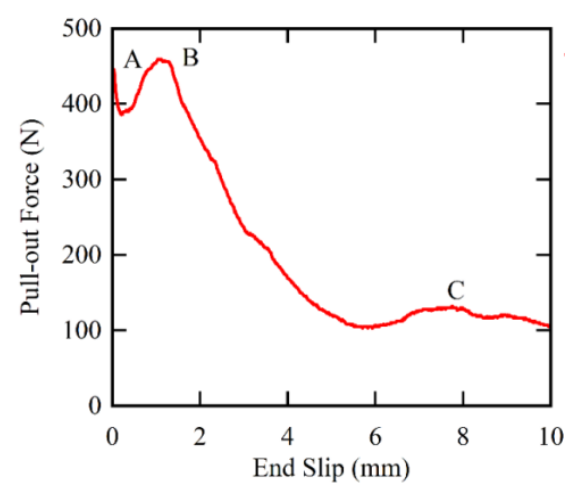

(b) SMA with $d_{\mathrm{f}}=2 \mathrm{~mm}$ and angle $90^{\circ}$ (No. 12)

Fig. 12 Different mechanisms created in the pull-out behavior of the fibers

In order to study more precisely the effect of different fiber parameters on the bond properties of the fibers with concrete, the effect of fiber hook angle, fiber diameter, and its material on pull-out responses, including pull-out force, slip related to the maximum pull-out force, pull-out energy, and effective pull-out stress, are shown in Table 5 for each case. Results show that pull-out force and total pull-out work (the area under the force-slip curve up to displacement of $10 \mathrm{~mm}$ ) increase with increasing hook angle for both the steel and the SMA fibers. As an example, it is observed that for the fibers with a diameter of $0.5 \mathrm{~mm}$, by increasing the hook angle from 0 to $40^{\circ}$, the pull-out force for the SMA and the steel fibers increases by about $33 \%$ and $30 \%$, respectively, while further increasing the hook angle decreases the pull-out parameters of the hooked-end fibers. In addition, it is observed that the work required for the SMA fibers pull-out is always greater than the corresponding value for the steel fibers. Therefore, it can be concluded that the use of SMA fibers significantly improves the pull-out of fibers. In the simulations performed in this study, due to the sufficient embedded length of the fiber (at least $10 \mathrm{~mm}$ ) and the complete hook movement during its pull-out and elongation, the maximum pull-out force occurs up to the angles about 40 degrees. However, the results of Soetens et al. [30] show that when the embedded length of the fiber is not sufficient to provide the bond in the matrix, and the hook end is not fully moved, the inclination angle has a minor impact on the pull-out behavior, and the maximum pull-out force remains almost unchanged according to the inclination angle.

In this study, finite element analysis has been used, so in order to further comprehensively investigate the results, more hook angles have been investigated and the important parameters of the pull-out force-displacement curve are summarized in Fig. 13. Fig. 13 summarizes several important pull-out parameters of SMA and steel fibers in UHPC according to the fiber 
diameter and hook angle. As shown in Fig. 13, the highest maximum pull-out force and pull-out work are found for hooked fibers at the angles about $40^{\circ}$, followed by the SMA and steel fibers. The maximum fiber bond stress of the hooked SMA fibers with $d_{\mathrm{f}}=0.5 \mathrm{~mm}, 1.5 \mathrm{~mm}$, and $2 \mathrm{~mm}$ is found to be $4.98 \mathrm{MPa}, 2.53 \mathrm{MPa}$, and 2.86 MPa, respectively, and it slightly decreases as the hook angle increases owing to the formation of matrix spalling. In addition, Fig. 13 shows that the fibers undergo a complete pullout process under 0 and 40 degrees, while sudden drops occur in the cases of 40 degrees because of fiber rupture or matrix spalling. As suggested by Robins et al. [31], fiber rupture and matrix spalling are the consequence of an accelerated intercrystal slippage due to additional bending stresses in the non-straight fiber. To be more specifically, fiber yield is the result of crystal slip caused by atomic-level dislocation movements. This slippage can be significantly accelerated when shear stresses are imposed on the fiber. For hooked fibers, the additional shear stresses on the fiber bending point can aid the slippage process and lower the strength of the metal. Consequently, the hooked fiber reaches the yield condition at a lower value of the applied load, thus a lower fracture load is achieved [31]. Furthermore, as it is seen from Fig. 13, for the SMA fibers, as the fiber diameter increases, the pull-out force increases, while the slip displacement or critical separation decreases.

Table 5 Effect of fiber hook angle, fiber diameter and its material on the pull-out force, slip of the maximum force point, pull-out energy, and effective pull-out stress

\begin{tabular}{|c|c|c|c|c|c|c|c|}
\hline $\begin{array}{l}\text { Sample } \\
\text { ID }\end{array}$ & $\begin{array}{l}\text { Fiber } \\
\text { type }\end{array}$ & $\begin{array}{l}\text { Fiber diameter } \\
(\mathrm{mm})\end{array}$ & $\begin{array}{c}\text { Hook angle } \\
\text { (degree) }\end{array}$ & $\begin{array}{l}\text { Pull-out } \\
\text { force }(\mathrm{N})\end{array}$ & $\begin{array}{c}\text { Critical } \\
\text { separation }(\mathrm{mm})\end{array}$ & $\begin{array}{c}\text { Pullout work } \\
\text { (N.mm) }\end{array}$ & $\begin{array}{c}\text { Bond stress } \\
(\mathrm{MPa})\end{array}$ \\
\hline No. 01 & SMA & \multirow{8}{*}{0.5} & \multirow{2}{*}{0} & 132.4 & 0.59 & 708 & 3.12 \\
\hline No. 13 & Steel & & & 116.7 & 0.78 & 376 & 2.88 \\
\hline No. 02 & SMA & & \multirow{2}{*}{20} & 148.2 & 0.84 & 792 & 3.78 \\
\hline No. 14 & Steel & & & 141.6 & 0.97 & 675 & 3.61 \\
\hline No. 03 & SMA & & \multirow{2}{*}{40} & 195.6 & 1.12 & 1126 & 4.98 \\
\hline No. 15 & Steel & & & 180.2 & 1.34 & 1043 & 4.59 \\
\hline No. 04 & SMA & & \multirow{2}{*}{90} & 174.7 & 0.92 & 952 & 4.45 \\
\hline No. 16 & Steel & & & 154.8 & 1.15 & 743 & 3.94 \\
\hline No. 05 & SMA & \multirow{8}{*}{1.5} & \multirow{2}{*}{0} & 169.3 & 0.40 & 893 & 1.44 \\
\hline No. 17 & Steel & & & 156.8 & 0.56 & 467 & 1.33 \\
\hline No. 06 & SMA & & \multirow{2}{*}{20} & 189.1 & 0.42 & 1043 & 1.61 \\
\hline No. 18 & Steel & & & 182.3 & 0.81 & 728 & 1.55 \\
\hline No. 07 & SMA & & \multirow{2}{*}{40} & 297.4 & 0.73 & 1608 & 2.53 \\
\hline No. 19 & Steel & & & 233.7 & 0.98 & 1405 & 1.98 \\
\hline No. 08 & SMA & & \multirow{2}{*}{90} & 229.4 & 0.44 & 1380 & 1.95 \\
\hline No. 20 & Steel & & & 200.8 & 0.87 & 1076 & 1.71 \\
\hline No. 09 & SMA & \multirow{8}{*}{2} & \multirow{2}{*}{0} & 239.3 & 0.29 & 1209 & 1.52 \\
\hline No. 21 & Steel & & & 221.5 & 0.08 & 978 & 1.41 \\
\hline No. 10 & SMA & & \multirow{2}{*}{20} & 298.2 & 0.21 & 2050 & 1.90 \\
\hline No. 22 & Steel & & & 266.7 & 0.18 & 1624 & 1.70 \\
\hline No. 11 & SMA & & \multirow{2}{*}{40} & 449.7 & 0.08 & 2952 & 2.86 \\
\hline No. 23 & Steel & & & 395.1 & 0.04 & 2762 & 2.52 \\
\hline No. 12 & SMA & & \multirow{2}{*}{90} & 367.2 & 0.12 & 2143 & 2.34 \\
\hline No. 24 & Steel & & & 335.4 & 0.10 & 2005 & 2.14 \\
\hline
\end{tabular}

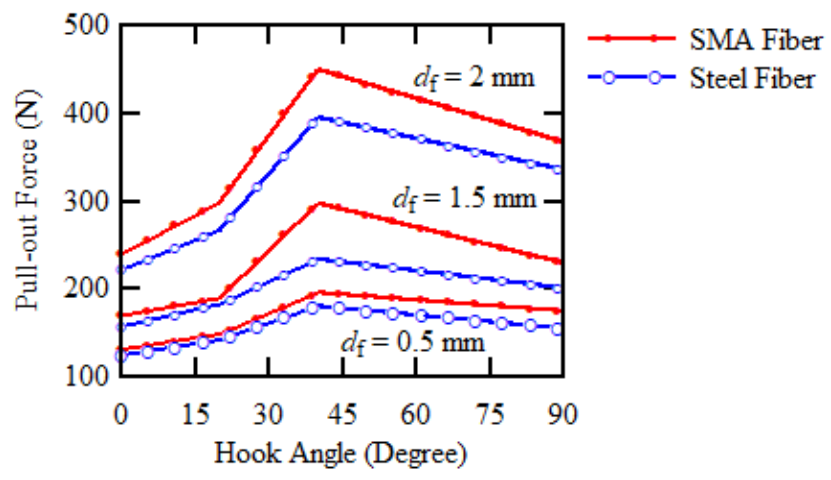

(a) Maximum pull-out force

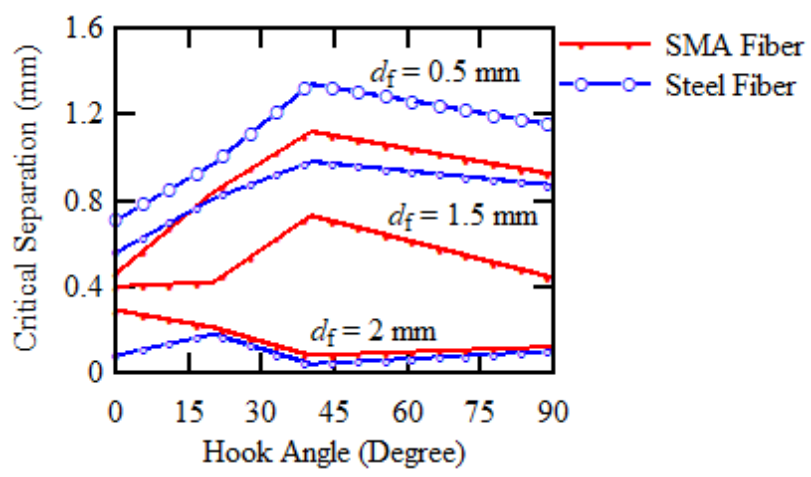

(b) Critical separation vs. hook angle

Fig. 13 Effect of hook angle and fiber diameter on the pull-out characteristics of SMA and steel fibers 


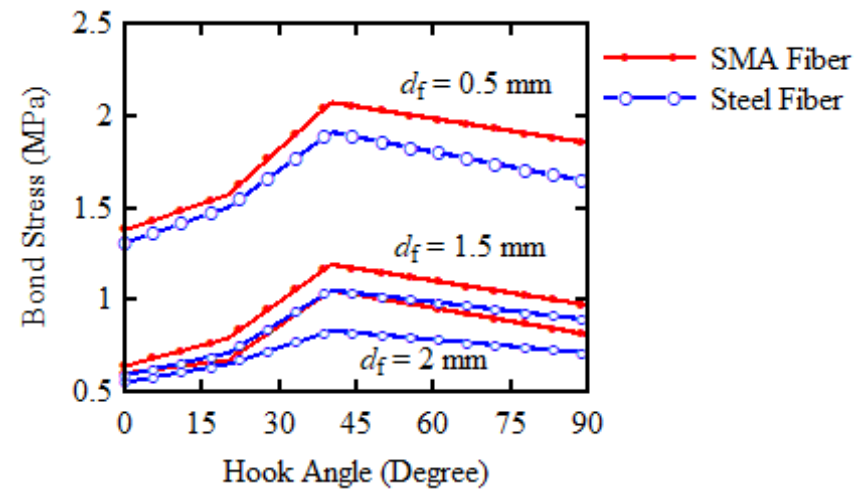

(c) Total work during pullout as functions of hook angle

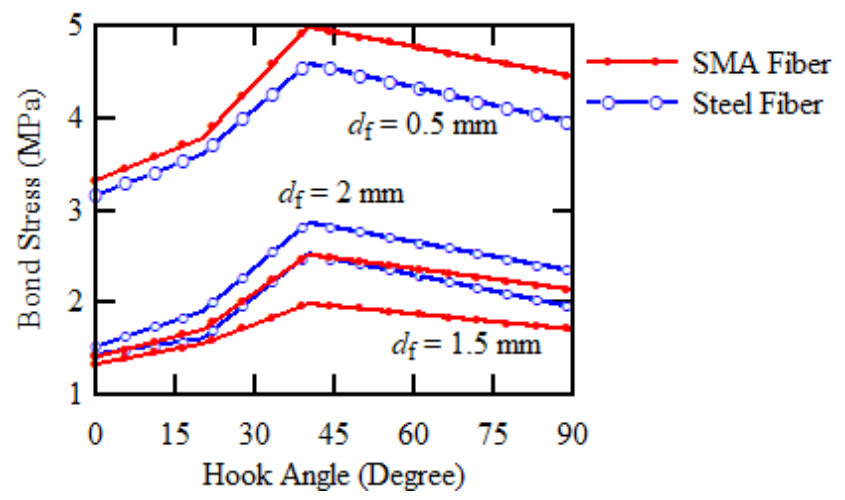

(d) Bond stress vs. hook angle

Fig. 13 Effect of hook angle and fiber diameter on the pull-out characteristics of SMA and steel fibers (continued)

\section{Conclusions}

This study investigated the effects of fiber-end shape on the pull-out resistance of the steel and super-elastic SMA fibers. For recognizing and realizing the pull-out behavior of the SMA fibers, a finite element model of pull-out has been performed by numerical model and employing single-fiber specimens. The interaction between the fibers and concrete has been simulated using the concept of bilinear cohesive zone model whose parameters have been obtained by using the results of experimental tests performed on a single fiber sample. Direct tensile and uniaxial compression tests have also been used to determine the tensile strength of UHPC. After the validation of the finite element model results with experimental data, the effect of fiber material, fiber diameter, and hook angle on the pull-out resistance are studied. The results show that:

(1) The SMA fibers have better pull-out resistance than the corresponding steel fibers.

(2) The maximum pull-out force is created at hook angles of about 40 degrees, which is due to the mechanisms such as the reduction of the pull-out force along with the fiber, the fiber bending at the curvature points, and the increase in frictional stress resulted from the component of the force perpendicular to the fiber at its curvature point.

(3) For the SMA fibers, as the fiber diameter increases, the pull-out force increases while the slip displacement decreases.

(4) Regarding the pull-out energy absorption of the hook-shaped fibers, the inclination fibers tend to absorb more energy than the straight fibers, and the maximum pull-out energy occurs at the inclination angles of about 40 degrees.

\section{Conflicts of Interest}

The authors declare no conflict of interest.

\section{References}

[1] M. Rezaee and V. A. Maleki, “An Analytical Solution for Vibration Analysis of Carbon Nanotube Conveying Viscose Fluid Embedded in Visco-Elastic Medium,” Proceedings of the Institution of Mechanical Engineers, Part C: Journal of Mechanical Engineering Science, vol. 229, no. 4, pp. 644-650, March 2015.

[2] J. Esmaeili and K. Andalibia, "Development of 3D Meso-Scale Finite Element Model to Study the Mechanical Behavior of Steel Microfiber-Reinforced Polymer Concrete," Computers and Concrete, vol. 24, no. 5, pp. 413-422, November 2019.

[3] J. Esmaeili, K. Andalibi, O. Gencel, F. K. Maleki, and V. A. Maleki, "Pull-Out and Bond-Slip Performance of Steel Fibers with Various Ends Shapes Embedded in Polymer-Modified Concrete," Construction and Building Materials, vol. 271, 121531, February 2021.

[4] G. Eslami, V. A. Maleki, and M. Rezaee, "Effect of Open Crack on Vibration Behavior of a Fluid-Conveying Pipe Embedded in a Visco-Elastic Medium,” Latin American Journal of Solids and Structures, vol. 13, no. 1, pp. 136-154, January 2016. 
[5] P. Vahidi Pashaki, M. Pouya, and V. A. Maleki, "High-Speed Cryogenic Machining of the Carbon Nanotube Reinforced Nanocomposites: Finite Element Analysis and Simulation," Proceedings of the Institution of Mechanical Engineers, Part C: Journal of Mechanical Engineering Science, vol. 232, no. 11, pp. 1927-1936, June 2018.

[6] Z. Çelik and A. F. Bingöl, "Fracture Properties and Impact Resistance of Self-Compacting Fiber Reinforced Concrete (SCFRC)," Materials and Structures, vol. 53, no. 3, 50, June 2020.

[7] A. Raza, "Experimental and Theoretical Study of GFRP Hoops and Spirals in Hybrid Fiber Reinforced Concrete Short Columns," Materials and Structures, vol. 53, no. 6, 139, December 2020.

[8] Z. Liu, R. Worley, F. Du, C. D. Giles, M. Dewoolkar, D. Huston, et al., "Avalanches During Flexure of Early-Age Steel Fiber Reinforced Concrete Beams," Materials and Structures, vol. 53, no. 4, 76, August 2020.

[9] S. Iqbal, I. Ali, S. Room, S. A. Khan, and A. Ali, "Enhanced Mechanical Properties of Fiber Reinforced Concrete Using Closed Steel Fibers," Materials and Structures, vol. 52, no. 3, 56, June 2019.

[10] K. Wille, A. E. Naaman, S. El-Tawil, and G. J. Parra-Montesinos, "Ultra-High Performance Concrete and Fiber Reinforced Concrete: Achieving Strength and Ductility without Heat Curing," Materials and Structures, vol. 45, no. 3, pp. 309-324, March 2012.

[11] S. Abdallah, M. Fan, and D. W. Rees, "Analysis and Modelling of Mechanical Anchorage of 4D/5D Hooked end Steel Fibres,” Materials \& Design, vol. 112, pp. 539-552, December 2016.

[12] G. Gebuhr, M. Pise, M. Sarhil, S. Anders, D. Brands, and J. Schröder, "Analysis and Evaluation of the Pull-Out Behavior of Hooked Steel Fibers Embedded in High and Ultra-High Performance Concrete for Calibration of Numerical Models," Structural Concrete, vol. 20, no. 4, pp. 1254-1264, 2019.

[13] M. Roig-Flores, F. Šimicevic, A. Maricic, P. Serna, and M. Horvat, "Interfacial Transition Zone in Mature Fiber-Reinforced Concretes,” ACI Materials Journal, vol. 115, no. 4, pp. 623-631, July 2018.

[14] J. Liu, N. Farzadnia, and C. Shi, "Effects of Superabsorbent Polymer on Interfacial Transition Zone and Mechanical Properties of Ultra-High Performance Concrete," Construction and Building Materials, vol. 231, 117142, January 2020.

[15] B. D. Ellis, D. L. McDowell, and M. Zhou, "Simulation of Single Fiber Pullout Response with Account of Fiber Morphology," Cement and Concrete Composites, vol. 48, pp. 42-52, April 2014.

[16] V. M. Cunha, J. A. Barros, and J. M. Sena-Cruz, "Pullout Behavior of Steel Fibers in Self-Compacting Concrete," Journal of Materials in Civil Engineering, vol. 22, no. 1, pp. 1-9, January 2010.

[17] J. M. Alwan, A. E. Naaman, and P. Guerrero, "Effect of Mechanical Clamping on the Pull-Out Response of Hooked Steel Fibers Embedded in Cementitious Matrices," Concrete Science and Engineering, vol. 1, no. 1, pp. 15-25, 1999.

[18] S. Abdallah and D. W. Rees, "Comparisons Between Pull-Out Behaviour of Various Hooked-End Fibres in Normal-High Strength Concretes," International Journal of Concrete Structures and Materials, vol. 13, no. 1, 27, December 2019.

[19] J. J. Kim and D. Y. Yoo, "Spacing and Bundling Effects on Rate-Dependent Pullout Behavior of Various Steel Fibers Embedded in Ultra-High-Performance Concrete," Archives of Civil and Mechanical Engineering, vol. 20, no. 2, 46, June 2020.

[20] M. Valipour and K. H. Khayat, "Debonding Test Method to Evaluate Bond Strength Between UHPC and Concrete Substrate," Materials and Structures, vol. 53, no. 1, 15, February 2020.

[21] J. Wei, C. Wu, Y. Chen, and C. K. Leung, "Shear Strengthening of Reinforced Concrete Beams with High Strength Strain-Hardening Cementitious Composites (HS-SHCC)," Materials and Structures, vol. 53, no. 4, 102, August 2020.

[22] C. O. Nwankwo and A. N. Ede, "Flexural Strengthening of Reinforced Concrete Beam Using a Natural Fibre Reinforced Polymer Laminate: An Experimental and Numerical Study," Materials and Structures, vol. 53, no. 6, 142, December 2020.

[23] W. S. Chang and Y. Araki, "Use of Shape-Memory Alloys in Construction: A Critical Review," Proceedings of the Institution of Civil Engineers-Civil Engineering, vol. 169, no. 2, pp. 87-95, May 2016.

[24] A. Abdulridha and D. Palermo, "Behaviour and Modelling of Hybrid SMA-Steel Reinforced Concrete Slender Shear Wall,” Engineering Structures, vol. 147, pp. 77-89, September 2017.

[25] M. S. Alam, M. A. Youssef, and M. Nehdi, "Analytical Prediction of the Seismic Behaviour of Superelastic Shape Memory Alloy Reinforced Concrete Elements," Engineering Structures, vol. 30, no. 12, pp. 3399-3411, December 2008.

[26] Y. Freed, J. Aboudi, and R. Gilat, "Thermomechanically Micromechanical Modeling of Prestressed Concrete Reinforced with Shape Memory Alloy Fibers," Smart Materials and Structures, vol. 16, no. 3, pp. 717-727, June 2007.

[27] K. Moser, A. Bergamini, R. Christen, and C. Czaderski, "Feasibility of Concrete Prestressed by Shape Memory Alloy Short Fibers," Materials and Structures, vol. 38, no. 5, pp. 593-600, June 2005.

[28] E. Preiß, "Fracture Toughness of Freestanding Metallic Thin Films Studied by Bulge Testing," Ph.D. dissertation, Technischen Fakultät, Friedrich-Alexander-Universität Erlangen-Nürnberg, Frankfurt am Main, 2018. 
[29] B. Zhou, S. H. Yoon, and J. S. Leng, “A Three-Dimensional Constitutive Model for Shape Memory Alloy,” Smart Materials and Structures, vol. 18, no. 9, 095016, September 2009.

[30] T. Soetens, A. Van Gysel, S. Matthys, and L. Taerwe, "A Semi-Analytical Model to Predict the Pull-Out Behaviour of Inclined Hooked-End Steel Fibres," Construction and Building Materials, vol. 43, pp. 253-265, June 2013.

[31] P. Robins, S. Austin, and P. Jones. "Pull-Out Behaviour of Hooked Steel Fibres," Materials and Structures, vol. 35, no. 7, pp. 434-442, August 2002.

Copyright $\odot$ by the authors. Licensee TAETI, Taiwan. This article is an open access article distributed under the terms and conditions of the Creative Commons Attribution (CC BY-NC) license (https://creativecommons.org/licenses/by-nc/4.0/). 